\title{
New use of sugar cane straw ash in alkali-activated materials: A silica source for the preparation of the alkaline activator
}

\author{
J.C.B. Moraes ${ }^{\mathrm{a}}$, A. Font ${ }^{\mathrm{b}}$, L. Soriano ${ }^{\mathrm{b}}$, J.L. Akasaki ${ }^{\mathrm{a}}$, M.M. Tashima ${ }^{\mathrm{a}}$, J. Monzó ${ }^{\mathrm{b}}$, M.V. Borrachero ${ }^{\mathrm{b}}$, \\ J. Payáa,* \\ ${ }^{a}$ Grupo de Pesquisa MAC - Materiais Alternativos de Construção, Universidade Estadual Paulista (UNESP), Faculdade de Engenharia de Ilha Solteira, Campus de Ilha Solteira, \\ Alameda Bahia, 550, 15385-000, Ilha Solteira, SP, Brazil \\ ${ }^{\mathrm{b}}$ GIQUIMA Group - Grupo de Investigación en Química de los Materiales de Construcción, Instituto de Ciencia y Tecnología del Hormigón (ICITECH), Universitat Politècnica de \\ Valencia, Valencia, Spain
}

\section{H I G H L I G H T S}

- Sugarcane straw ash (SCSA) was used as activator for alkali activated material (AAM).

- The new activator was prepared by reaction of SCSA with $\mathrm{NaOH}$.

- The SCSA-based activator was used for the alkali activation of blastfurnace slag.

- Similar behaviour for SCSA and rice husk ash (RHA) was observed.

- SCSA was a good silica source for replacing sodium silicate in AAM.

\section{A R T I C L E I N F O}

\section{Article history:}

Received 18 January 2018

Received in revised form 20 March 2018

Accepted 23 March 2018

\section{Keywords:}

Conservation

Thermal treatment

Microstructure

Compressive strength

Alkali-activated cement

\begin{abstract}
A B S T R A C T
Alkali silicates, expensive and highly pollutant chemical reagents, are required to produce the alkaline activator for high-performance alkali-activated materials. This study presents a new silica source for producing the alkaline activator, sugar cane straw ash (SCSA). An activating suspension was prepared with SCSA and NaOH by means of a thermal bottle. The ash reacting time inside the thermal bottle $(\tau)$ was assessed from 0 to $48 \mathrm{~h}$, and the SCSA amount in suspension, represented by the $\mathrm{SiO}_{2} / \mathrm{Na}_{2} \mathrm{O}$ ratio $(\varepsilon)$, was analysed from 0 to 1.82 . Compressive strengths were obtained from blast-furnace slag-based mortars that were cured for three days at $65{ }^{\circ} \mathrm{C}$, with the optimal mortars produced when $\tau=24 \mathrm{~h}$ and $\varepsilon=1.46$. Comparison of these new SCSA systems with two common silica sources, sodium silicate chemical reagent and rice husk ash, revealed that SCSA yielded lower results than the former and similar results to the latter silica source.
\end{abstract}

(c) 2018 Elsevier Ltd. All rights reserved.

\section{Introduction}

Alkali-activated materials (AAMs) are alternative binders to Portland cement. Their advantages over Portland cement are lower energy consumption and reduced $\mathrm{CO}_{2}$ emissions during the manufacturing process $[1,2]$. AAMs are obtained by mixing an amorphous aluminosilicate (solid precursor) with an alkaline activator (also called by activating solution or alkaline solution), where the product from this chemical reaction hardens and forms a material with interesting mechanical properties [1,2]. Examples of common solid precursors are blast-furnace slag (BFS), metakaolin and fly

\footnotetext{
* Corresponding author.

E-mail address: jjpaya@cst.upv.es (J. Payá).
}

ash. The most common reagents in alkaline solutions are alkali hydroxides and silicates [1,2].

The use of waste materials in AAM production has become a recent trend [3-5]. This study describes the utilisation of sugar cane straw ash (SCSA), an ash rich in amorphous silica $\left(\mathrm{SiO}_{2}\right)$, in AAM production. The management of this waste is a particular interest due the recent increase of sugar cane production in Brazil. In 2014, this country produced 736.11 million tonnes of sugar cane were produced, which accounts for $\sim 40 \%$ of the worldwide production [6]. The potential of SCSA in AAM comes from prior studies that assessed its reactivity as pozzolan in calcium hydroxide blends [7-9]. Authors observed that the ash presented high reactivity $[7,8]$, where the SCSA activity was also compared to a densified silica fume [9]. The justification for such SCSA reactivity is due the presence of the amorphous phase (mainly silica) observed in 
X-ray diffraction. In the tests carried out, SCSA consumed large amount of calcium hydroxide to form C-S-H (calcium silicate hydrate) gels. This reaction product was observed in the following tests: X-ray diffraction [7], thermogravimetric analysis [7,9], Fourier transform infrared spectroscopy and electrical conductivity measurement [9]. As consequence for the high consumption of calcium hydroxide observed in these studies, SCSA was utilised as partial replacement of the Portland cement. Authors concluded that the replacement percentage range of $20-30 \%$ presented similar mechanical behaviour than the control [10-12]. The pozzolanic characteristic of the SCSA was the reason for such good results: the consumption of portlandite was observed by thermogravimetric analysis [10] and X-ray diffraction [11]. Related to the use of SCSA in AAM, the ash was previous studied as solid precursor in a binary system with blast furnace slag [13]. The samples of blast furnace slag and SCSA presented higher compressive strength than the control since 3 days of curing at $25^{\circ} \mathrm{C}$. Authors observed that the amorphous silica from SCSA improved the blast furnace slag matrix, explaining the great results. Now, this study presents another use of SCSA in AAM production, with SCSA being utilised as a source of silica in the production an alkaline suspension (alkaline activator).

The $\mathrm{SiO}_{4}^{4-}$ anion is a key component in high-performance AAMs, because it favours the formation of a denser and stronger structure $[1,2]$. Sodium silicate (SS) currently provides an important reactive part of silica that is widely used in combination with sodium hydroxide to produce the activating solution [1,2]. However, the main disadvantages of SS are mainly due that it is the most expensive raw material to produce AAM and the highest emitter of greenhouse gases among the basic materials [14-17]. The cost of the sodium silicate can be around of $20 \%$ to produce a AAM concrete, depending on the dosage. About the greenhouse gases, authors found that emissions from the production of the sodium silicate represents a $50-70 \%$ of the total in an AAM concrete design. This high value is due the melting of the raw materials (silica and sodium carbonate) until $1400{ }^{\circ} \mathrm{C}$ to produce the sodium silicate [17]. One of the key research targets in the near future will thus be the assessment of new sources of silica to produce the activating solution due the sodium silicate disadvantages $[18,19]$. One of the key research targets in the near future will thus be the assessment of new sources of silica to produce the activating solution [20-25]. Results from these studies about new silica source to the alkaline activator will be discussed in the Results and Discussions section, where they will be compared to the use of SCSA to the same purpose.

The main objective of this study is to assess the potential of employing SCSA as the silica source to prepare the alkaline suspension (alkaline activator). SCSA was utilised in combination with sodium hydroxide to produce an aqueous $\mathrm{NaOH} / \mathrm{SCSA}$ suspension by means of a thermal bottle. The resulted blend of water, $\mathrm{NaOH}$ and SCSA were not filtered, resulting in a suspension and not in a solution. The study is divided into three parts: 1 ) deriving the optimum time for dissolving the ash to prepare the activating reagent; 2 ) understanding the influence of SCSA on the activating reagent; and 3) comparing SCSA to commercial SS chemical reagents and alternative silica sources. After this study, it is expected to produce an alkaline reagent with best SCSA content and the finest dissolution time in a thermal bottle.

\section{Experimental}

\subsection{Materials and equipment}

BFS was supplied by Cementval S.A., Puerto de Sagunto, Spain, in the form of large grains, which was then milled in a ball mill for 30 min to obtain a fine material that could be used as the solid precursor in AAM production. The chemical composition of BFS is shown in Table 1 . BFS is primarily composed of $\mathrm{CaO}, \mathrm{SiO}_{2}, \mathrm{Al}_{2} \mathrm{O}_{3}$ and $\mathrm{MgO}$. Its mean particle diameter $\left(D_{\text {mean }}\right)$ was $25.6 \mu \mathrm{m}$. Sodium hydroxide $(\mathrm{NaOH}$, or $\mathrm{NH}$ in the context of solution composition and specimens nomenclature) is the chemical reagent utilised to prepare the alkaline solutions and suspensions. This material was used in form of pellets, and was supplied by Panreac S.A., with a purity of $98 \%$. Natural sand from Caolines Lapiedra (Lliria, Valencia, Spain), with a fineness modulus of 4.30 , was utilised to prepare the mortars.

SCSA was utilised as the silica source to produce the activating suspension. The ash preparation process consisted of the following steps. The straw was first collected from sugar cane plantations near Ilha Solteira city (São Paulo, Brazil), and then transformed to ash by means of an autocombustion process. This procedure took $6 \mathrm{~h}$, and a maximum temperature of $700{ }^{\circ} \mathrm{C}$ was observed during the combustion process. The ash was then sieved (MESH \#50; $300 \mu \mathrm{m}$ ) to remove any unburned particles. To complete the process, the sieved ash was milled in a ball mill for $50 \mathrm{~min}$. This milling process was carried out to reduce liquid absorption capability of the ash and, consequently, enhancing rheological properties of the fresh AAM. Table 1 shows the chemical composition of SCSA, with $\mathrm{SiO}_{2}$ (58.6 wt\%), $\mathrm{Al}_{2} \mathrm{O}_{3}$ (9.0 wt\%) and $\mathrm{Fe}_{2} \mathrm{O}_{3}$ (8.4 wt\%) being the most abundant compounds. $D_{\text {mean }}=18.1 \mu \mathrm{m}$ after the milling process. The amount of insoluble residue was also determined for SCSA (34 wt\%).

RHA was another silica source utilised to produce the activating suspension. This ash served as a comparison material to SCSA. RHA was supplied by DACSA S.A., Tabernes Blaques, Spain, and it was utilised as received $\left(D_{\text {mean }}=62.3 \mu \mathrm{m}\right)$. Its chemical composition is summarized in Table 1 , with the main oxide being $\mathrm{SiO}_{2}$ (85.6 wt\%). The RHA was not milled prior to use, because a previous study concluded that the particle diameter of this ash did not influence the mechanical AAM properties [20]. Unlike RHA, the use of unground SCSA presented rheological problems during the AAM preparation due to considerable water adsorption, thus requiring SCSA to be milled to achieve the appropriate workability of the samples.

Commercial SS was also utilised as a silica source. This chemical reagent was acquired from Merck, and its chemical composition was $8 \mathrm{wt} \% \mathrm{Na}_{2} \mathrm{O}, 28 \mathrm{wt} \% \mathrm{SiO}_{2}$ and $64 \mathrm{wt} \% \mathrm{H}_{2} \mathrm{O}$.

\subsection{Preparation of alkali-activated materials}

Three parameters were held constant during the AAM analysis, with the water/BFS ratio, sand/BFS ratio (for mortars) and $\mathrm{Na}^{+}$ molality fixed at $0.45,3.0$ and $4 \mathrm{~mol} \cdot \mathrm{kg}^{-1}$, respectively. The preparation of the alkaline suspension and solution played an important role in this study, with two different suspensions and two different solutions analysed: $\mathrm{NH} / \mathrm{SCSA}, \mathrm{NH} / \mathrm{RHA}$ (both are suspensions), $\mathrm{NH}$

Table 1

Chemical composition of BFS, SCSA and RHA, in wt\%.

\begin{tabular}{|c|c|c|c|c|c|c|c|c|c|c|}
\hline Raw materials & $\mathrm{SiO}_{2}$ & $\mathrm{Al}_{2} \mathrm{O}_{3}$ & $\mathrm{Fe}_{2} \mathrm{O}_{3}$ & $\mathrm{CaO}$ & $\mathrm{MgO}$ & $\mathrm{K}_{2} \mathrm{O}$ & $\mathrm{SO}_{3}$ & $\mathrm{Cl}$ & Others & LOI \\
\hline BFS & 29.9 & 10.6 & 1.3 & 40.2 & 7.4 & 0.6 & 1.9 & - & 2.6 & 5.5 \\
\hline SCSA & 58.6 & 9.0 & 8.4 & 4.6 & 1.6 & 5.4 & 1.9 & 0.7 & 3.3 & 6.5 \\
\hline RHA & 85.6 & 0.3 & 0.2 & 1.8 & 0.5 & 3.4 & 0.3 & 0.3 & 0.6 & 7.0 \\
\hline
\end{tabular}


only (NH/-) and NH/SS (both are solutions). The amount of SCSA, RHA and SS used to produce the alkaline solution is represented in terms of the $\mathrm{SiO}_{2} / \mathrm{Na}_{2} \mathrm{O}$ molar ratio in the solution $(\varepsilon)$. Here $\varepsilon$ can only be varied by the amount of silica source that is added to the activating solution, because the $\mathrm{Na}^{+}$molality is fixed. Cases with $\varepsilon=0.73,1.09,1.46$ and 1.82 were assessed for the SCSA containing suspensions, whereas $\varepsilon=1.46$ was the only case that was assessed for SS and RHA. $\varepsilon=0$ was the only case assessed for the pure $\mathrm{NaOH}$ solution.

The NH/SCSA and NH/RHA activating suspensions were produced by means of a thermal bottle. The use of a thermal bottle was beneficial, because the $\mathrm{NaOH}$ dissolution in water releases heat, thus improving the dissolution rate of the ash particles. The ash (SCSA or RHA) was first dry mixed with $\mathrm{NaOH}$ in the thermal bottle, followed by the addition of water over the solids (the water/NaOH/SCSA mass ratio in $\mathrm{g}$ was $202.5 / 32.4 / \mathrm{x}$, where $\mathrm{x}=29.5,44.3,59.0$ and 73.8 for $\varepsilon=0.73,1.09,1.46$ and 1.82 respectively) and the stirring of the solution for one minute. The thermal bottle was then sealed with a cap, and monitored to determined time necessary to dissolve the ash $(\tau)$. Activating suspensions were obtained instead of activating solutions for the instances where some of the ash would not dissolve. Here tests with $\tau=0 \mathrm{~h}$ (in this case, the ash was added as the solid precursor together with BFS), $6 \mathrm{~h}, 24 \mathrm{~h}$ and $48 \mathrm{~h}$ were conducted for SCSA, whereas $\tau=24 \mathrm{~h}$ was the test conducted for RHA. The temperature of the sodium hydroxide solution $\left(4 \mathrm{~mol} \cdot \mathrm{kg}^{-1}\right)$ inside the thermal bottle was also monitored during the production of the activating suspension (Fig. 1). The water was $32{ }^{\circ} \mathrm{C}$ prior to being mixed with sodium hydroxide (0h). The system reached $58{ }^{\circ} \mathrm{C}$ after $5 \mathrm{~min}$ and started to decrease until $6 \mathrm{~h}$, when the temperature of the suspension reached a constant temperature of $\sim 35^{\circ} \mathrm{C}$. The suspension was left in the thermal bottle until it returned to room temperature after the thermal bottle treatment. The prepared suspensions were not filtered prior to use. The solutions composed of $\mathrm{NaOH}$ and $\mathrm{NaOH} /$ SS were prepared by mixing the chemical reagents with water in a common beaker. The beaker was then sealed with a plastic film, and the solution was left to reach room temperature.

Manufacturing of the mortars consisted of mixing BFS with the prepared suspensions or solutions until proper homogenisation was attained $(60 \mathrm{~s})$. The prepared paste was then stirred with nat- ural sand $(150 \mathrm{~s})$. The resulting mortar was vibrated in a prismatic mould $\left(40 \times 40 \times 160 \mathrm{~mm}^{3}\right)$, and then stored under controlled temperature $\left(20^{\circ} \mathrm{C}\right.$ or $\left.65^{\circ} \mathrm{C}\right)$ and relative humidity (100\%) conditions until the compressive strength tests were conducted. The pastes produced for the microstructural analyses were made under the same conditions as the mortars.

\subsection{Test procedures}

Compressive strength tests were carried out on mortars by means of a universal test machine, following the UNE-EN 196-1 standard [26]. Pastes were assessed with XRD, FTIR, TGA and FESEM techniques. XRD patterns were obtained by a Bruker AXS D8 Advance with a voltage of $40 \mathrm{kV}$, a current intensity of $20 \mathrm{~mA}$ and a Bragg's angle $(2 \theta)$ in the $5-70^{\circ}$ range, with a step of $0.02^{\circ}$ at 2 s/step. FTIR spectra were acquired with a Bruker Tensor 27 and analysed in the $400-4000 \mathrm{~cm}^{-1}$ range. TGA were performed with a TGA Mettler-Toledo TGA 850, where the specimen was heated in a $70 \mu \mathrm{L}$ alumina crucible to the $35-1000{ }^{\circ} \mathrm{C}$ temperature range, at a heating rate of $20^{\circ} \mathrm{C} \cdot \mathrm{min}^{-1}$ and in the presence of a dry air atmosphere $\left(75 \mathrm{~mL} \cdot \mathrm{min}^{-1}\right.$ gas flow). The amount of sample utilised in TGA test was $35.0 \pm 1.0 \mathrm{mg}$. Mass loss and derivative curves (DTG curves) were extracted from the TG curve. FESEM images were taken using a ZEISS Supra 55, with the fractured surface sample covered with carbon. The extra high tension was $20 \mathrm{kV}$ and the working distance was 6-8 $\mathrm{mm}$ for the energy dispersive X-ray spectroscopy (EDS).

Mortars and pastes were assessed after three days of curing at $65{ }^{\circ} \mathrm{C}$ and $100 \%$ relative humidity. Mortars and pastes were also assessed after 28 days of curing at $20^{\circ} \mathrm{C}$ and $100 \%$ relative humidity for a series of comparative compressive strength tests (see Section 3). Table 2 summarizes the tests performed and the selected mixtures assessed for each test.

\subsection{Alkali-activated materials studies}

This study was divided into three parts to assess the potential of SCSA as a silica source in the preparation of the activating suspension: 1) to obtain the optimum treatment time on leaving the ash in the thermal bottle $(\tau) ; 2$ ) to determine the optimal amount of

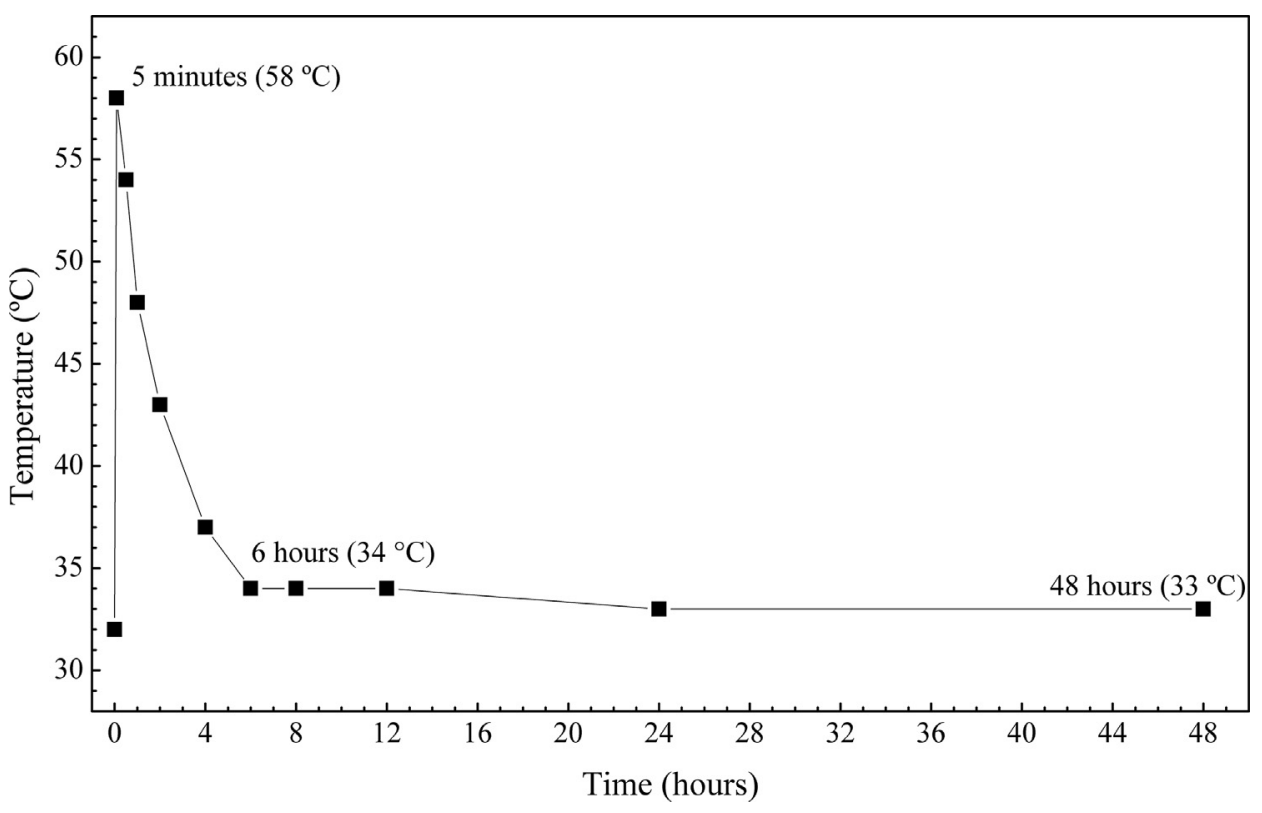

Fig. 1. Temperature evolution of the dissolution of sodium hydroxide $(32.4 \mathrm{~g})$ in water $(202.5 \mathrm{~g})$ inside the thermal bottle. 
Table 2

Mixtures and tests carried out.

\begin{tabular}{|c|c|c|c|c|c|c|}
\hline \multirow{2}{*}{$\begin{array}{l}\text { Study } \\
\text { Section }\end{array}$} & \multirow{2}{*}{$\begin{array}{l}\text { Activating Suspension or } \\
\text { Solution }\end{array}$} & \multirow{2}{*}{$\begin{array}{l}\mathrm{SiO}_{2} / \mathrm{Na}_{2} \mathrm{O} \text { molar } \\
\text { ratio }(\varepsilon)\end{array}$} & \multirow{2}{*}{$\begin{array}{l}\text { Thermal bottle } \\
\text { time }(\tau)\end{array}$} & \multirow[t]{2}{*}{ Nomenclature } & \multicolumn{2}{|l|}{ Testing ages } \\
\hline & & & & & $\begin{array}{l}\text { Compressive strength } \\
\text { tests }\end{array}$ & $\begin{array}{l}\text { Microstructural tests (XRD, FTIR, TG } \\
\text { and FESEM) }\end{array}$ \\
\hline \multirow[t]{4}{*}{1} & $\mathrm{NH} / \mathrm{SCSA}$ & 1.46 & 0 & SCSA-1.46-0 & 3 days $\left(65^{\circ} \mathrm{C}\right)$ & 3 days \\
\hline & & & 6 & SCSA-1.46-6 & & - \\
\hline & & & 24 & SCSA-1.46-24 & & 3 days \\
\hline & & & 48 & SCSA-1.46-48 & & - \\
\hline \multirow[t]{5}{*}{2} & $\mathrm{NH} /-$ & 0 & - & $\mathrm{NH}-\mathrm{O}$ & 3 days $\left(65^{\circ} \mathrm{C}\right)$ & 3 days \\
\hline & $\mathrm{NH} / \mathrm{SCSA}$ & 0.73 & 24 & SCSA-0.73-24 & & - \\
\hline & & 1.09 & & SCSA-1.09-24 & & - \\
\hline & & 1.46 & & SCSA-1.46-24 & & 3 days \\
\hline & & 1.82 & & SCSA-1.82-24 & & - \\
\hline \multirow[t]{3}{*}{3} & $\mathrm{NH} / \mathrm{SS}$ & 1.46 & - & SS-1.46 & 3 days $\left(65^{\circ} \mathrm{C}\right)$ and 28 & 3 days \\
\hline & $\mathrm{NH} / \mathrm{SCSA}$ & & 24 & SCSA-1.46-24 & days $\left(20^{\circ} \mathrm{C}\right)$ & 3 days \\
\hline & NH/RHA & & 24 & RHA-1.46-24 & & - \\
\hline
\end{tabular}

SCSA in the activating suspension ( $\varepsilon$; ; and 3) to compare the $\mathrm{NH} /$ SCSA suspension to different silica sources (NH/SS (solution) and $\mathrm{NH} / \mathrm{RHA}$ (suspension) systems). Both $\tau$ and $\varepsilon$ were determined from the compressive strengths of the mortars after three days of curing at $65{ }^{\circ} \mathrm{C}$. In the first part, four time intervals $(\tau=0 \mathrm{~h}, 6 \mathrm{~h}$, $24 \mathrm{~h}$ and $48 \mathrm{~h}$ ) were assessed, with $\varepsilon=1.46$, to obtain the optimal $\tau$. In the second part, the influence of the SCSA amount was assessed by varying the $\varepsilon$, with $\varepsilon=0$ (solution with only $\mathrm{NaOH}$ ), $0.73,1.09,1.46$ and 1.82 (common $\varepsilon$ values in the alkaline activation of BFS [27]), and maintaining a constant time $(\tau=24 \mathrm{~h})$. In the third component, the NH/SCSA suspensions, with $\varepsilon=1.46$ and $\tau=24 \mathrm{~h}$, were compared to $\mathrm{NH} / \mathrm{SS}$ and $\mathrm{NH} / \mathrm{RHA}$ systems with the same $\varepsilon$ and $\tau$. Four silica mixtures were selected and manufactured into pastes to study their microstructures: two produced by the activating solution with $\mathrm{NH} / \mathrm{SCSA}(\varepsilon=1.46, \tau=0 \mathrm{~h}$ and $24 \mathrm{~h})$; one produced by a solution of $\mathrm{NaOH}(\varepsilon=0)$; and one produced by a solution of $\mathrm{NH} / \mathrm{SS}(\varepsilon=1.46)$.

The nomenclature adopted for these dosages is $\mathrm{X}-\varepsilon-\tau$, where $\mathrm{X}$ is the alkaline suspension or solution system $(\mathrm{NH}, \mathrm{SCSA}$, RHA or SS), $\varepsilon$ is the $\mathrm{SiO}_{2} / \mathrm{Na}_{2} \mathrm{O}$ molar ratio and $\tau$ is only defined for the suspension with SCSA and RHA. Table 2 summarizes the three parts of the study, the dosages assessed and their respective nomenclatures.

\section{Results and discussion}

\subsection{Effect of $\tau$ on SCSA/NaOH suspensions}

The compressive strengths of SCSA-1.46-0, SCSA-1.46-6, SCSA1.46-24 and SCSA-1.46-48 after three days of curing at $65^{\circ} \mathrm{C}$ are shown in Fig. 2. It is observed that $\tau$ had a crucial effect on the compressive strength development of the mortar, with strengthening observed for $\tau \leq 24 \mathrm{~h}$. The SCSA-1.46-24 mortar showed the highest compressive strength $(45.0 \mathrm{MPa})$. These results appear to suggest that the use of thermal bottle accelerated the silica dissolution from SCSA in the activating suspension. The increased presence of $\mathrm{SiO}_{4}^{4-}$ anions in the alkaline suspension probably favoured the formation of more cementing gel when it reacted with BFS. The high suspension temperature (maximum of $58^{\circ} \mathrm{C}$ ) observed during the first $6 \mathrm{~h}$ (Fig. 1) favoured the SCSA dissolution, with a marked increase in compressive strength development between SCSA1.46-0 and SCSA-1.46-6. However, some SCSA dissolution must be carried out due the high alkaline conditions after the suspension reached a constant temperature after $6 \mathrm{~h}$, leading to the increased compressive strength of SCSA-1.46-24. Alternatively, it may not be advantageous to utilise the thermal bottle beyond $\tau=24 \mathrm{~h}$, as the compressive strength of SCSA-1.46-48 (41.8 MPa) was only slightly lower than that of SCSA-1.46-24. It was observed that the alkaline suspension produced from SCSA for $\tau=48 \mathrm{~h}$ suffered gelification as reported for RHA [20]. This gel likely did not take part in the formation of the AAM products, thus contributing to the decrease in compressive strength. Therefore, it can be concluded that $\tau=24 \mathrm{~h}$ is the optimum thermal bottle time for SCSA.

The XRD patterns for the raw materials (BFS and SCSA) and the SCSA-1.46-24 and SCSA-1.46-0 pastes (cured after three days at $65^{\circ} \mathrm{C}$ ) are shown in Fig. 3. The baseline deviation observed in the diffractograms of the raw materials and pastes was due the presence of the amorphous phase in their compositions. The baseline deviation was observed in the Bragg's Angle range of $22-37^{\circ}$ and $17-35^{\circ}$ in the BFS and SCSA diffractograms, respectively. The baseline deviation of the ash was only detected after the enlargement of the diffractogram due the large quantity of quartz. There were no differences among the baseline deviations of the prepared pastes, suggesting that they all formed a similar gel of the form

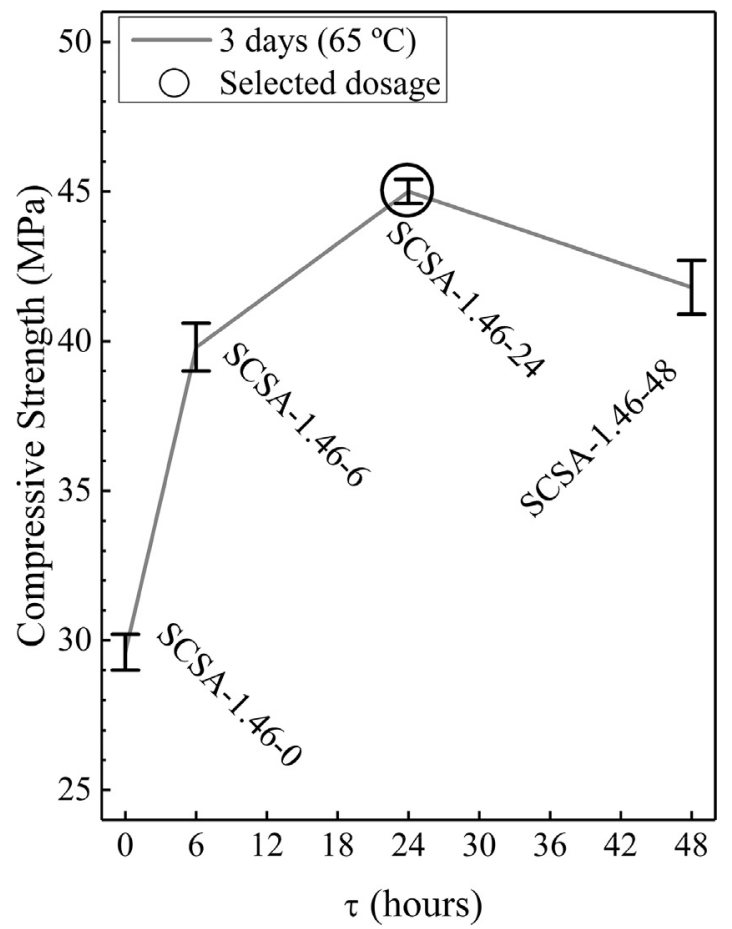

Fig. 2. Compressive strength of four mortars (cured at $65{ }^{\circ} \mathrm{C}$ for three days), with the activator prepared by thermal bottle treatment with $\varepsilon=1.46$ and $\tau=0 \mathrm{~h}, 6 \mathrm{~h}, 24$ $\mathrm{h}$ and $48 \mathrm{~h}$. 


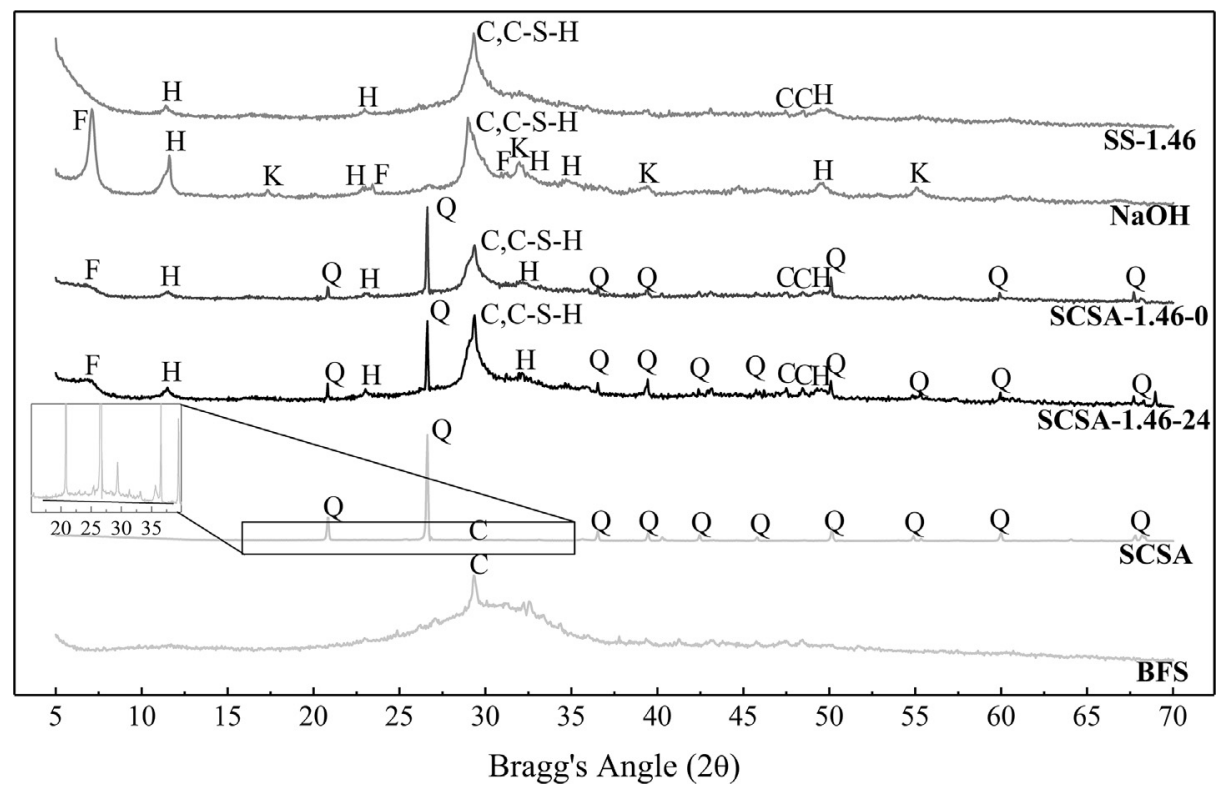

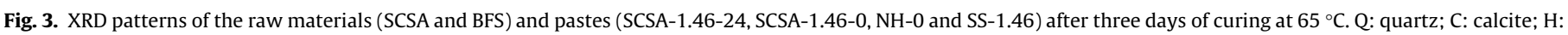
hydrotalcite; F: faujasite; C-S-H: calcium silicate hydrate; K: katoite.

(N,C)-A-S-H [28]. Crystalline compounds were also observed on the diffractograms. Calcite $\left(\mathrm{CaCO}_{3}\right.$, PDF Card \#050586; BFS and SCSA) and quartz $\left(\mathrm{SiO}_{2}\right.$, PDF Card \#331161; SCSA) were detected on the XRD patterns of the raw materials. Faujasite $\left(\mathrm{Na}_{2} \mathrm{Al}_{2} \mathrm{Si}_{4} \mathrm{O}_{12} \cdot 8 \mathrm{H}_{2} \mathrm{O}\right.$, PDF Card \#391380), hydrotalcite $\left(\mathrm{Mg}_{6} \mathrm{Al}_{2} \mathrm{CO}_{3}(\mathrm{OH})_{16} \cdot \mathrm{H}_{2} \mathrm{O}\right.$, PDF Card \#140191) and a C-S-H phase (probably a (C,N)-A-S-H phase due to the presence of sodium and aluminium in the reaction) were detected on the XRD patterns of the pastes. The broad XRD peak associated with this gel overlapped the main calcite XRD peak. However, other peaks related to the presence of calcite were also observed, which indicates that some slight carbonation of the samples took place either during the curing process or in the sample handling. SCSA-1.46-24 and SCSA-1.46-0 were analysed in greater detail to determine the influence of $\tau$. Whilst both pastes presented similar diffractogram patterns, some key differences were observed. The main band for the C-S-H gel in the $28.3-30.3^{\circ}$ range also varied in size, with the paste prepared in the thermal bottle possessing stronger intensities than the sample produced by SCSA and without the bottle treatment. The areas under the main XRD peaks for quartz $\left(A_{O}\right)$ and C-S-H $\left(A_{g e l}\right)$ were measured with the OriginPro 8 graphing software package in the range of the analysed peak and without taking the baseline deviation into account. The area ratio, $\phi=A_{\text {gel }} / A_{Q}$, was calculated for both pastes. $\phi=5.58$ for SCSA-1.46-24, whereas $\phi=2.87$ for SCSA-1.46-0. Assuming the quartz fraction in SCSA was not dissolved during the preparation of the suspension and did not react with BFS, these $\phi$ values suggest the formation of more reaction products when $\tau=24 \mathrm{~h}$.

The FTIR spectra of the raw materials (BFS and SCSA) and pastes (SCSA-1.46-24 and SCSA-1.46-0) after three days of curing at $65^{\circ} \mathrm{C}$ are presented in Fig. 4. The main bands detected in the spectra for the raw materials and pastes were in the wavenumber ranges of $800-1250 \mathrm{~cm}^{-1}$ (stretching mode of Si-O) and $1400-1550 \mathrm{~cm}^{-1}$ (stretching mode of $\mathrm{O}-\mathrm{C}-\mathrm{O}$ bonds). The band in the 1400-1550 $\mathrm{cm}^{-1}$ range was due to the presence of calcite in the raw materials and minimal carbonation of the samples, as observed in the XRD analysis. Here the most important wavenumber interval is 800 $1250 \mathrm{~cm}^{-1}$, because the main differences among the spectra are observed within this wavenumber range. BFS and SCSA possessed broad bands in the $800-1050 \mathrm{~cm}^{-1}$ and $900-1250 \mathrm{~cm}^{-1}$ wavenumber ranges, respectively, while the pastes showed narrower bands in the $900-1050 \mathrm{~cm}^{-1}$ interval, with a peak centred near $950 \mathrm{~cm}^{-1}$. This behaviour is justified by the bonds breaking of the raw material particles and the subsequent formation of AAM products [29]. No significant differences were observed between the two pastes produced with SCSA, indicating that their gels are similar.

The TGA results are represented in Fig. 5 (DTG curves) and Table 3 (mass losses) for the SCSA-1.46-24 and SCSA-1.46-0 pastes

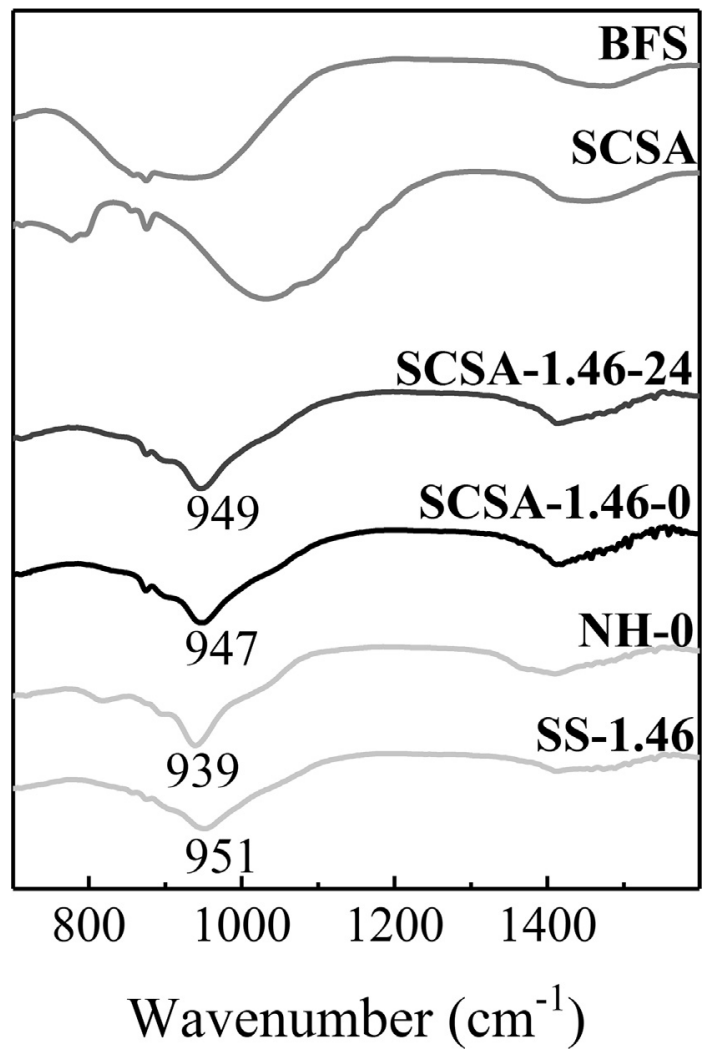

Fig. 4. FTIR spectra of the raw materials (SCSA and BFS) and pastes (SCSA-1.46-24, SCSA-1.46-0, NH-0 and SS-1.46) after three days of curing at $65^{\circ} \mathrm{C}$. 


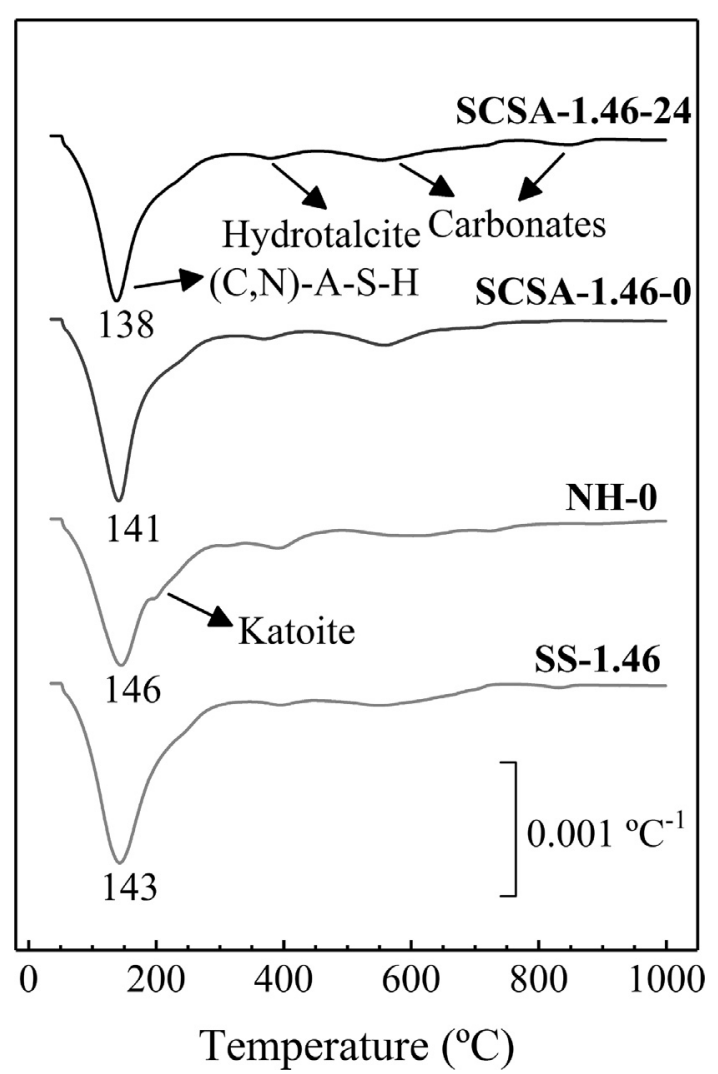

Fig. 5. DTG curves of the pastes (SCSA-1.46-24, SCSA-1.46-0, NH-0 and SS-1.46) after three days of curing at $65{ }^{\circ} \mathrm{C}$ (numbers close to main peaks are in ${ }^{\circ} \mathrm{C}$ ).

after three days of curing at $65^{\circ} \mathrm{C}$. Four peaks were observed on the DTG curves of these pastes at the following temperatures: $140^{\circ} \mathrm{C}$, $400{ }^{\circ} \mathrm{C}, 550^{\circ} \mathrm{C}$ and $800^{\circ} \mathrm{C}$. The first peak, centred at $140{ }^{\circ} \mathrm{C}$, was related to the decomposition of the (C,N)-A-S-H or N-A-S-H products. The peak at $400^{\circ} \mathrm{C}$ was identified as the decomposition of hydrotalcite, and the peaks at $550{ }^{\circ} \mathrm{C}$ and $800^{\circ} \mathrm{C}$ were related to the decomposition of carbonates [30]. Normally, carbonates decompose in the $700-850{ }^{\circ} \mathrm{C}$ temperature range. However, the formation of a poorly crystallised phase and the presence of sodium ions can cause a decrease in the decomposition temperature of the carbonates to $550{ }^{\circ} \mathrm{C}$ [30]. Table 3 shows the mass losses for the two different temperature intervals to the importance of temperature on the formation of the reaction products: $35-300{ }^{\circ} \mathrm{C}\left(\mathrm{P}_{35-300}\right)$ and $300-1000{ }^{\circ} \mathrm{C}\left(\mathrm{P}_{300-1000}\right)$. Similar mass losses were also observed in the $35-300^{\circ} \mathrm{C}$ temperature range (12.67\% and $11.68 \%$ for SCSA-1.46-0 and SCSA-1.46-24, respectively), suggesting that the amount of combined water of the reaction products was in the same order of magnitude. This fact means that the differences in the compressive strengths are not directly related to the percentage of combined water, and may thus be analysed based on the distribution of products in the cementing matrix.

\section{Table 3}

Mass losses (\%) of the SCSA-1.46-24, SCSA-1.46-0, NaOH and SS-1.46 pastes after three days of curing at $65^{\circ} \mathrm{C}$ over the $35-300{ }^{\circ} \mathrm{C}\left(\mathrm{P}_{35-300}\right)$ and $300-1000{ }^{\circ} \mathrm{C}\left(\mathrm{P}_{300-1000}\right)$ test temperature intervals.

\begin{tabular}{llll}
\hline \multirow{2}{*}{ Specimen } & \multicolumn{2}{l}{ Mass Losses $(\%)$} \\
\cline { 2 - 4 } & $\mathrm{P}_{35-300}$ & $\mathrm{P}_{300-1000}$ & TOTAL \\
\hline SCSA-1.46-24 & 11.68 & 5.57 & 17.25 \\
SCSA-1.46-0 & 12.67 & 5.06 & 17.73 \\
NaOH & 12.40 & 5.76 & 18.16 \\
SS-1.46 & 14.50 & 5.19 & 19.69 \\
\hline
\end{tabular}

The FESEM micrographs for the SCSA-1.46-24 paste after three days of curing at $65{ }^{\circ} \mathrm{C}$ are shown in Fig. 6 . A dense and amorphous structure was observed on the fractured surface paste (as suggested from the XRD test; Fig. 6a). A compacted gel and unreacted particles of BFS (Spot A) were also identified. No unreacted SCSA particles were found. The formed gels (Spot B) can be seen at a higher magnification in Fig. $6 \mathrm{~b}$ and $\mathrm{c}$. They appear as very small and irregular particles $(<0.2 \mu \mathrm{m}$ in diameter $)$ that are piled against each other in a homogeneous pattern, yielding a low porosity matrix. EDS analysis of this gel (seven points) yielded the following molar ratios: $\mathrm{Ca} / \mathrm{Si}=0.95 \pm 0.07, \mathrm{Al} / \mathrm{Si}=0.32 \pm 0.03, \mathrm{Na} / \mathrm{Al}=1.34 \pm$ 0.05 and $\mathrm{Mg} / \mathrm{Si}=0.13 \pm 0.05$. Table 4 shows the EDS results represented by molar contents for each element utilised to calculate these ratios from spots $\mathrm{B}$. This gel is considered to be a (C,N)-A$\mathrm{S}-\mathrm{H}$ product. Some potassium (K) was detected in EDS results, where it comes from the chemical composition from the SCSA. The magnesium observed in the EDS analysis can be related to both possibilities: EDS detected an unreacted slag under the formed products or the presence of hydrotalcite among the gels [31]. Fig. 6d highlights some microcrystals (Spot C) that are distributed in the gel matrix (probably faujasite crystals).

The FESEM images for the SCSA-1.46-0 paste after three days of curing at $65{ }^{\circ} \mathrm{C}$ are shown in Fig. 7. A dense structure, similar to SCSA-1.46-24, is observed at Spot D on Fig. 7a. Fig. 7b shows a quartz particle from SCSA in Spot E surrounded by gel. The magnifications of Fig. 7a are shown in Fig. 7c and d. The formed gel is also composed of small hydration products, similar to those found on SCSA-1.46-24. The molar ratios of the gel on SCSA-1.46-0 were: $C$ $\mathrm{a} / \mathrm{Si}=0.92 \pm 0.06, \mathrm{Al} / \mathrm{Si}=0.33 \pm 0.01, \mathrm{Na} / \mathrm{Al}=1.86 \pm 0.12$ and $\mathrm{Mg} / \mathrm{S}$ $\mathrm{i}=0.18 \pm 0.05$. The $\mathrm{Ca} / \mathrm{Si}, \mathrm{Al} / \mathrm{Si}$ and $\mathrm{Mg} / \mathrm{Si}$ ratios on SCSA $-1.46-0$ were similar to those observed on SCSA-1.46-24. Table 5 presents the molar content for each element that was obtained to calculate the molar ratio values from Spot D. The largest difference was between the two pastes was the $\mathrm{Na} / \mathrm{Al}$ ratio of the formed gel, despite both pastes possessing the same composition.

It has been reported that the strength development of AAMs depends on the $\varepsilon$ value of the activating solution, with the low compressive strength of BFS systems attributed to cases where $\varepsilon$ $<1.0$ [32]. The theoretical $\varepsilon$ value was 1.46 in both SCSA pastes. However, there was less solubilised silica in SCSA-1.46-0, which means that the real $\varepsilon$ of SCSA-1.46-0 is lower than that for SCSA$1.46-24$. More $\mathrm{Na}^{+}$is thus incorporated into the formed gel in this situation, which significantly lowers the strength of the sample (34.2\% lower strength; see Fig. 2). Therefore, the chemical composition of the formed gel formed makes a critical contribution to the strength of the matrix.

\subsection{Effect of $\varepsilon$ on the $\mathrm{SCSA} / \mathrm{NaOH}$ suspensions}

The compressive strengths of NH-0, SCSA-0.73-24, SCSA-1.0924, SCSA-1.46-24 and SCSA-1.82-24 after three days of curing at $65{ }^{\circ} \mathrm{C}$ are shown in Fig. 8. The SCSA amount, which is represented by $\varepsilon$, clearly influences the compressive strength of the mortars at a constant $\tau(24 \mathrm{~h})$. The increase in $\varepsilon$ also generates an increase in the compressive strength of mortars. A noticeable result is that all the ash samples (compressive strength results in the 26.9-47.8 MPa range) yield significantly better results than the mortar with only $\mathrm{NaOH}(14.1 \mathrm{MPa})$. As expected, the dissolved $\mathrm{SiO}_{4}^{4-}$ from SCSA promotes the formation of a stronger structure. The dosage selected for the final component of the analysis was SCSA-1.46-24. Whilst SCSA-1.82-24 (47.8 MPa) possessed a slightly higher compressive strength than SCSA-1.46-24 (45.0 MPa), the latter mortar presented better rheological properties than the former one.

Correlation of the compressive strength results in Figs. 2 and 8 highlights the important role of SCSA in the reaction process without the thermal bottle. SCSA-1.46-0 possessed a compressive 


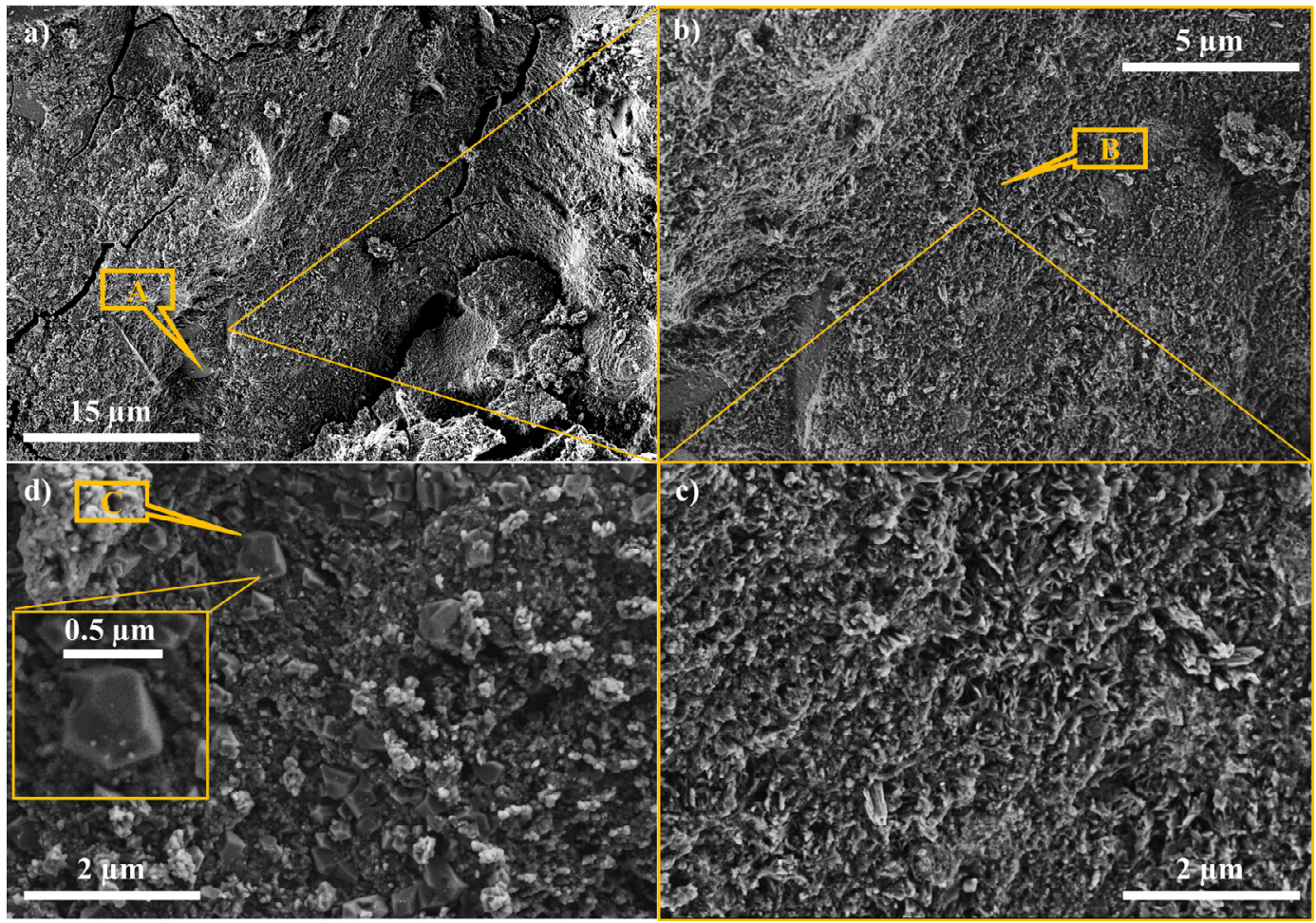

Fig. 6. FESEM micrographs of the SCSA-1.46-24 paste.

Table 4

Molar content (in \%) of the elements at points related to Spot B from SCSA-1.46-24 paste.

\begin{tabular}{|c|c|c|c|c|c|c|c|}
\hline \multirow[t]{2}{*}{ Spot } & \multicolumn{6}{|c|}{ Element (molar, \%) } & \multirow[t]{2}{*}{ TOTAL (\%) } \\
\hline & $\mathrm{Si}$ & $\mathrm{Al}$ & $\mathrm{Na}$ & $\mathrm{Ca}$ & K & $\mathrm{Mg}$ & \\
\hline Spot B - 1 & 34.89 & 10.24 & 14.40 & 35.00 & 1.35 & 4.12 & 100 \\
\hline Spot B - 2 & 33.88 & 12.21 & 14.42 & 31.00 & 2.12 & 6.37 & 100 \\
\hline Spot B - 3 & 33.34 & 10.44 & 14.14 & 35.36 & 1.28 & 5.44 & 100 \\
\hline Spot B -4 & 35.32 & 12.49 & 14.27 & 31.22 & 0.97 & 5.73 & 100 \\
\hline Spot B - 5 & 36.89 & 10.45 & 16.45 & 33.13 & 1.46 & 1.61 & 100 \\
\hline Spot B - 6 & 37.18 & 10.54 & 14.18 & 33.49 & 1.49 & 3.12 & 100 \\
\hline Spot B - 7 & 34.89 & 10.24 & 14.40 & 35.00 & 1.35 & 4.12 & 100 \\
\hline
\end{tabular}

strength that was $113 \%$ greater than that of $\mathrm{NH}-0$ (30.0 and 14.1 MPa, respectively; Fig. 8). Furthermore, SCSA-1.46-0 possessed a higher compressive strength than SCSA-0.73-24 (26.9 MPa) and a similar value to SCSA-1.09-24 (31.0 MPa). These results demonstrate that a sample produced without the thermal bottle can possess a similar (or even higher) compressive strength when compared to a sample produced with a thermal bottle. However, when mixtures with the same $\varepsilon$ value and different $\tau$ values are compared (e.g., SCSA-1.46-0 and SCSA-1.46-24), the samples produced with the thermal bottle possessed higher compressive strengths than those produced without it, as observed in Fig. 2.

The XRD results highlight the key differences between the $\mathrm{NaOH}$ and SCSA-1.46-24 pastes (Fig. 3). The $\mathrm{NaOH}$ sample possessed more intense peaks of the crystalline phases (faujasite and hydrotalcite) than the SCSA sample, with the formation of katoite also observed in the $\mathrm{NaOH}$ sample. Previous studies have also noted the high formation of crystalline compounds, with more ordered phases produced by a pure $\mathrm{NaOH}$ solution than a solution that is a combination of sodium hydroxide and a silica source (e.g., SS) $[33,34]$. The advanced formation of these ordered structures supports the lower compressive strength results of the $\mathrm{NaOH}$ samples.
FTIR analysis revealed that the main Si-O peak of the SCSA paste was located at a higher wavenumber than the $\mathrm{NaOH}$ paste (Fig. 4). The increase in the silica content of the SCSA system in the mixture likely produced a stronger gel, thus causing the mortars produced with SCSA to possess higher compressive strengths.

The TGA studies showed that the $\mathrm{NaOH}$ sample underwent a mass loss similar to the other pastes, even though it possesses a lower compressive strength (Fig. 5 and Table 3). XRD analysis of the $\mathrm{NaOH}$ sample indicated the strong formation of crystalline compounds, such as faujasite and katoite $\left(\mathrm{Ca}_{3} \mathrm{Al}_{2}\left(\mathrm{SiO}_{4}\right)(\mathrm{OH})_{8}\right.$, PDF Card \#380368), that decompose at $\sim 140{ }^{\circ} \mathrm{C}$ and $\sim 200{ }^{\circ} \mathrm{C}$, respectively. The decomposition of alkali-activated materials gels was also observed at these temperatures. A bulk of the mass loss of the $\mathrm{NH}-0$ sample in the $35-300{ }^{\circ} \mathrm{C}$ temperature range is likely related to the crystalline phase decompositions, with dehydration due to the cementing gels having a secondary effect. This observation explains why the mass loss of the $\mathrm{NH}-0$ specimen was comparable to the other pastes, even though the compressive strength was very low.

Fig. 9 shows the FESEM micrographs of the $\mathrm{NH}-0$ sample after three days of curing at $65^{\circ} \mathrm{C}$. The structure of the $\mathrm{NH}-0$ paste was more crystalline and porous than the SCSA pastes. This kind 

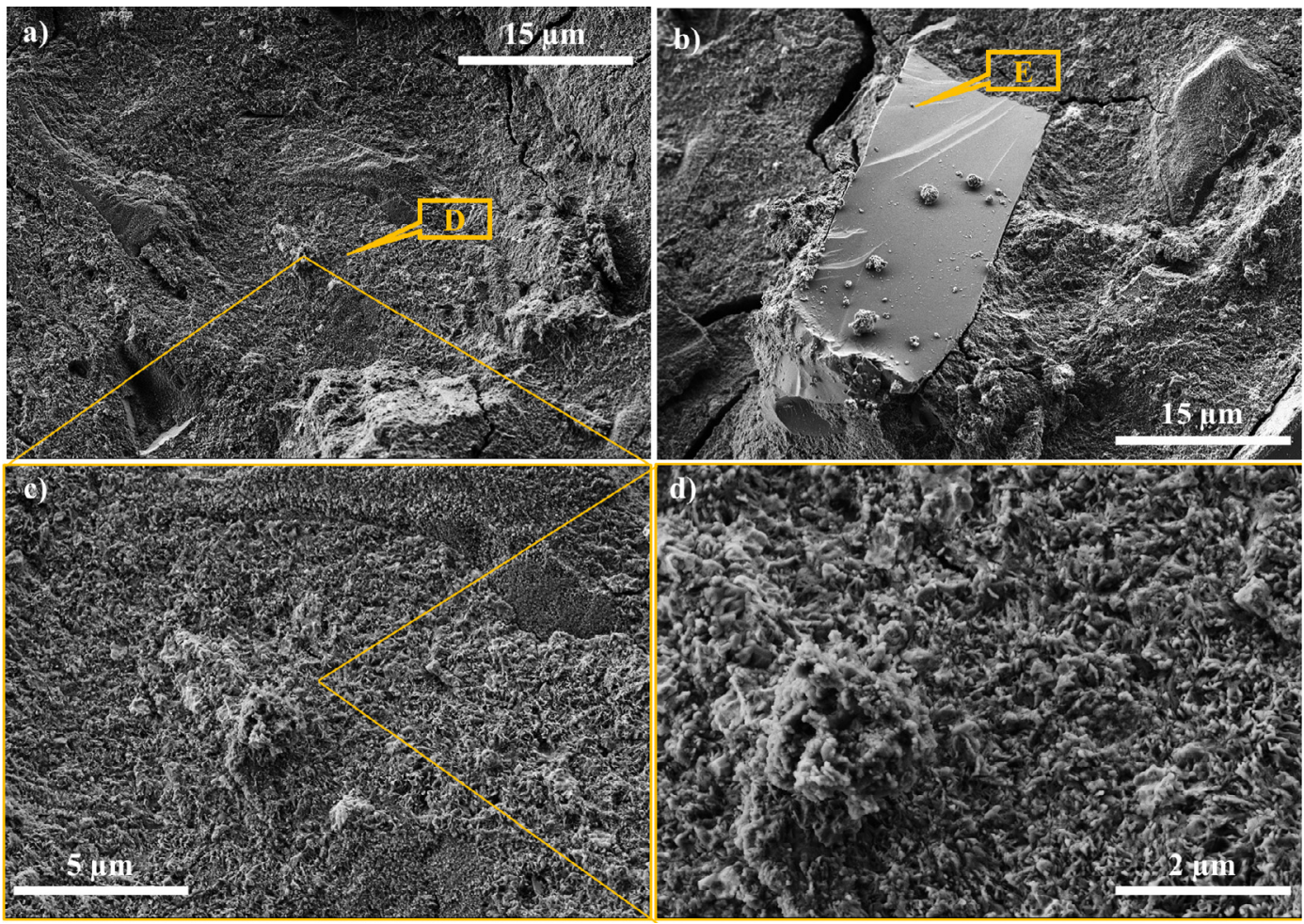

Fig. 7. FESEM micrographs of the SCSA-1.46-0 paste.

Table 5

Molar content (in \%) of the elements at points related to spots D from SCSA-1.46-0 paste.

\begin{tabular}{|c|c|c|c|c|c|c|c|}
\hline \multirow[t]{2}{*}{ Spot } & \multicolumn{6}{|c|}{ Element (molar, \%) } & \multirow[t]{2}{*}{ TOTAL $(\%)$} \\
\hline & $\mathrm{Si}$ & Al & $\mathrm{Na}$ & $\mathrm{Ca}$ & K & $\mathrm{Mg}$ & \\
\hline Spot D - 1 & 32.10 & 10.95 & 19.30 & 28.31 & 1.77 & 7.58 & 100 \\
\hline Spot D - 2 & 32.82 & 10.56 & 21.07 & 29.20 & 2.07 & 4.29 & 100 \\
\hline Spot D - 3 & 31.75 & 10.38 & 19.06 & 31.33 & 1.78 & 5.70 & 100 \\
\hline
\end{tabular}

of structure was already expected due to our prior analyses. The molar ratios of the gel on $\mathrm{NH}-0$ were: $\mathrm{Ca} / \mathrm{Si}=1.18 \pm 0.02, \mathrm{Al} / \mathrm{Si}=0$ $.38 \pm 0.02, \mathrm{Na} / \mathrm{Al}=1.89 \pm 0.15$ and $\mathrm{Mg} / \mathrm{Si}=0.07 \pm 0.01$. Table 6 presents the molar content for each element obtained from EDS results. The $\mathrm{Ca} / \mathrm{Si}$ ratio for $\mathrm{NH}-0$ was higher than those from the SCSA pastes (1.18 vs. 0.92-0.95). It is clearly noticed that the NH-0 paste possessed less silicon than the SCSA samples, which probably led to the formation of a more crystalline, porous and softer structure with a lower compressive strength.

\subsection{Comparison of SCSA to other silica sources}

The compressive strength of SCSA-1.46-24 was compared to SS1.46 and RHA-1.46-24 after three days of curing at $65^{\circ} \mathrm{C}$, and also after 28 days of curing at $20^{\circ} \mathrm{C}$ (Fig. 10). SS-1.46 possessed the highest compressive strength, with 62.9 MPa and 78.8 MPa observed for the 3-day (at $65^{\circ} \mathrm{C}$ ) and 28 -day (at $20^{\circ} \mathrm{C}$ ) curing times, respectively. The two ash systems, SCSA and RHA, yielded similar results. SCSA possessed compressive strengths of $45 \mathrm{MPa}$ and $54.9 \mathrm{MPa}$ for 3 days and 28 days, respectively, whereas RHA reached $49.7 \mathrm{MPa}$ and 59.7 MPa for the same curing ages. Curing at $20^{\circ} \mathrm{C}$ yielded higher compressive strengths in all cases. Although $\varepsilon$ was equal for the three mixtures, the presence of non-dissolved silica from the ashes (SCSA and RHA) likely caused the lower compressive strengths. It was difficult to determine the amount of solubilised silica after the treatment in the thermal bottle, because the gelifica- tion of the suspension impeded filtration of the solution. However, it was obvious that the quartz present in SCSA was not dissolved, which thus generated less solubilised silica. This is the likely reason for the slightly higher compressive strengths of the RHA samples.

SCSA has the potential to be utilised as a silica source to produce the activating suspension, even though SCSA possessed only $75-80 \%$ of the compressive strength obtained for SS-1.46. Spent diatomaceous earth was analysed in a previous study that assessed the production of alternative solutions in a fly ash/metakaolin system [22]. However, the compressive strength of the pastes obtained from this solution was only $\sim 50 \%$ of the strength of the SS control. The spent diatomaceous earth sample also yielded similar results to RHA. Waste glass has also been utilised as a silica source to produce the activating solution [23]. The pastes produced by the activating solution with glass waste from a BFS-based system possessed $\sim 75-80 \%$ of the compressive strength of the control, which is similar to the SCSA results presented here. More recently, sugar cane bagasse ash was evaluated as a silica source in the production of the activating solution [25]. This new solution yielded similar results in compressive strength tests to those from waste glass and RHA in metakaolin-based AAM.

The XRD patterns of SCSA-1.46-24 and SS-1.46 possessed several differences (Fig. 3). The main one was the obvious absence of quartz in SS-1.46. The SCSA-1.46-24 diffractogram also highlighted the presence of faujasite, which was not observed in the SS-1.46 sample. Low intensity peaks that corresponded to 


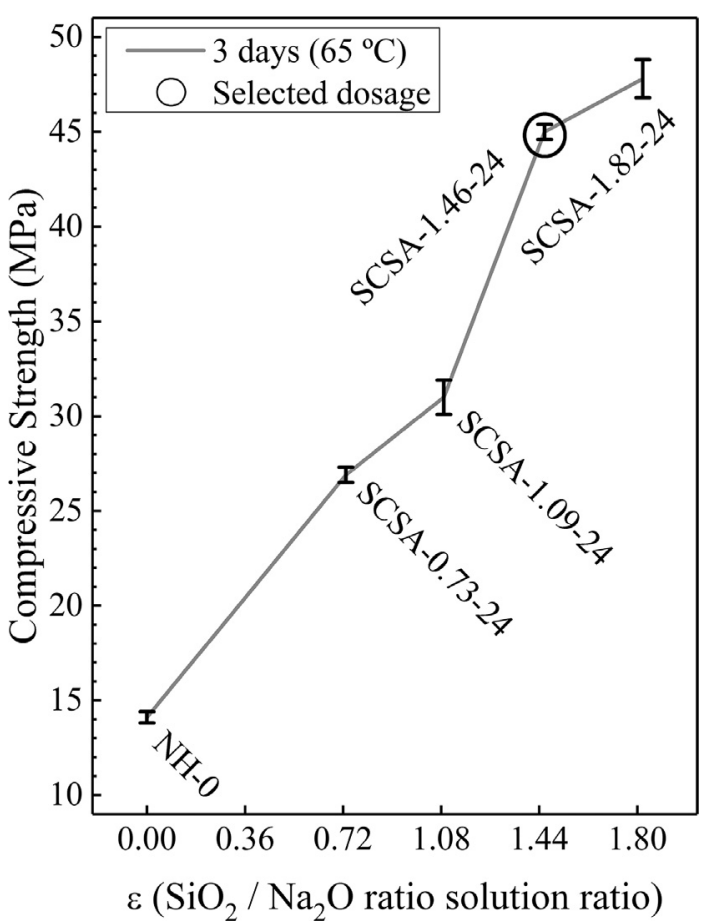

Fig. 8. Compressive strength of the mortars after three days of curing at $65{ }^{\circ} \mathrm{C}$, with the activator prepared by thermal bottle treatment and $\varepsilon=0$ (only $\mathrm{NaOH}$ ), 0.73 , $1.09,1.46$ and 1.82 .

hydrotalcite and calcite were also identified in SS-1.46. These XRD observations and the higher soluble silica content explain why SS1.46 possessed the highest compressive strength.

The FTIR studies (Fig. 4) did not differentiate between SCSA$1.46-24$ and SS-1.46, as only a small difference in the energy of the main $\mathrm{Si}-\mathrm{O}$ band exists. This result suggests that the chemical nature of the formed hydrates is similar.

The mass loss of SS-1.46 was higher than that of SCSA-1.46-24 (Fig. 5 and Table 3). This is likely due to the increased formation of

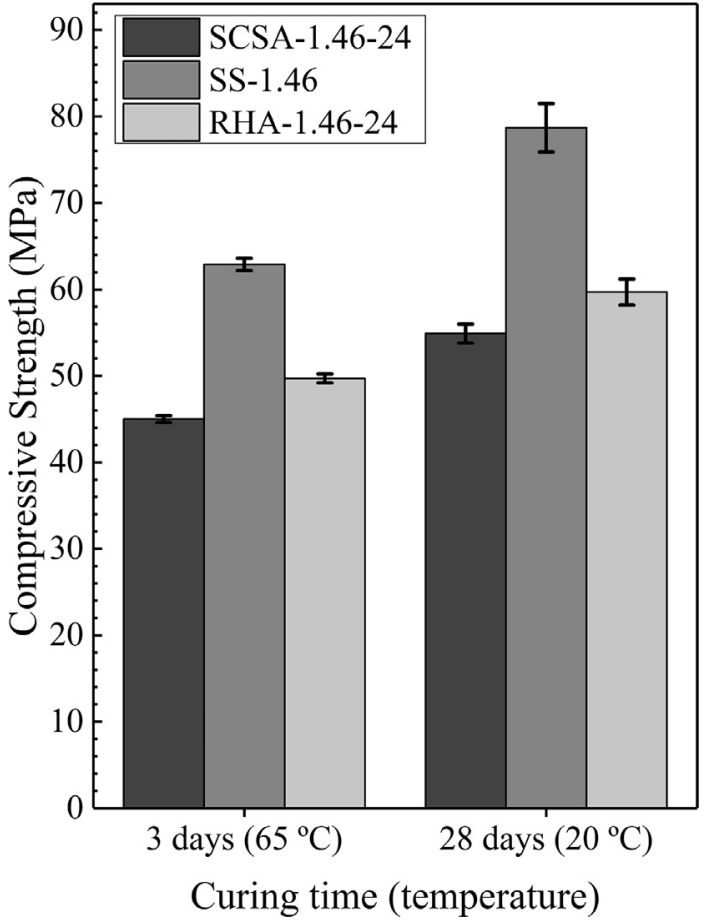

Fig. 10. Comparison of the compressive strengths of three mortars (cured at $65{ }^{\circ} \mathrm{C}$ for 3 days and $20^{\circ} \mathrm{C}$ for 28 days) obtained from SCSA, SS and RHA.

cementing gels in SS-1.46, which also justifies the higher compressive strength. The shapes of the DTG curves of both SCSA pastes are also more similar to the specimen produced with SS than $\mathrm{NaOH}$, with a large peak related to the mass loss due to the dehydration of (C,N)-A-S-H products and no peaks related to decomposition of C-A-S-H compounds. This behaviour suggests that the SCSA and SS pastes produce similar products.

The FESEM micrographs of the SS-1.46 paste after three days of curing at $65{ }^{\circ} \mathrm{C}$ are depicted in Fig. 11. This paste possesses an

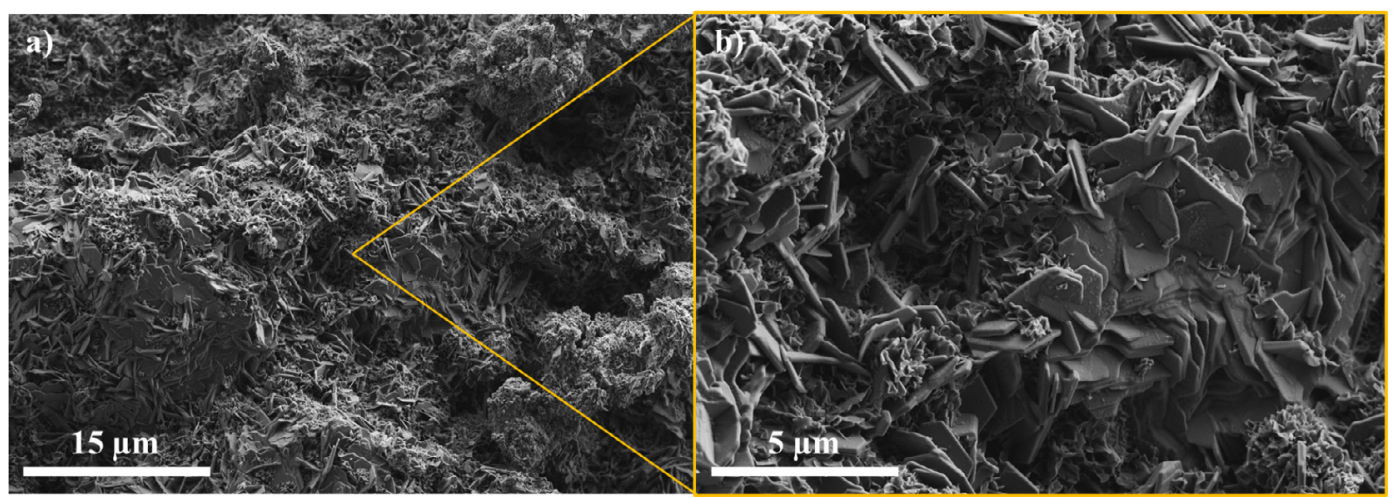

Fig. 9. FESEM micrographs of the NH-0 paste.

Table 6

Molar content (in \%) of the elements at points related to gel formation from NH-0 paste.

\begin{tabular}{|c|c|c|c|c|c|c|c|}
\hline \multirow[t]{2}{*}{ Spot } & \multicolumn{6}{|c|}{ Element (molar, \%) } & \multirow[t]{2}{*}{ TOTAL (\%) } \\
\hline & $\mathrm{Si}$ & $\mathrm{Al}$ & $\mathrm{Na}$ & $\mathrm{Ca}$ & K & $\mathrm{Mg}$ & \\
\hline Gel - 1 & 30.17 & 10.58 & 21.87 & 35.04 & 0.00 & 2.34 & 100 \\
\hline Gel - 2 & 29.60 & 11.85 & 21.12 & 35.11 & 0.00 & 2.33 & 100 \\
\hline Gel - 3 & 30.00 & 11.36 & 20.85 & 35.87 & 0.00 & 1.92 & 100 \\
\hline
\end{tabular}



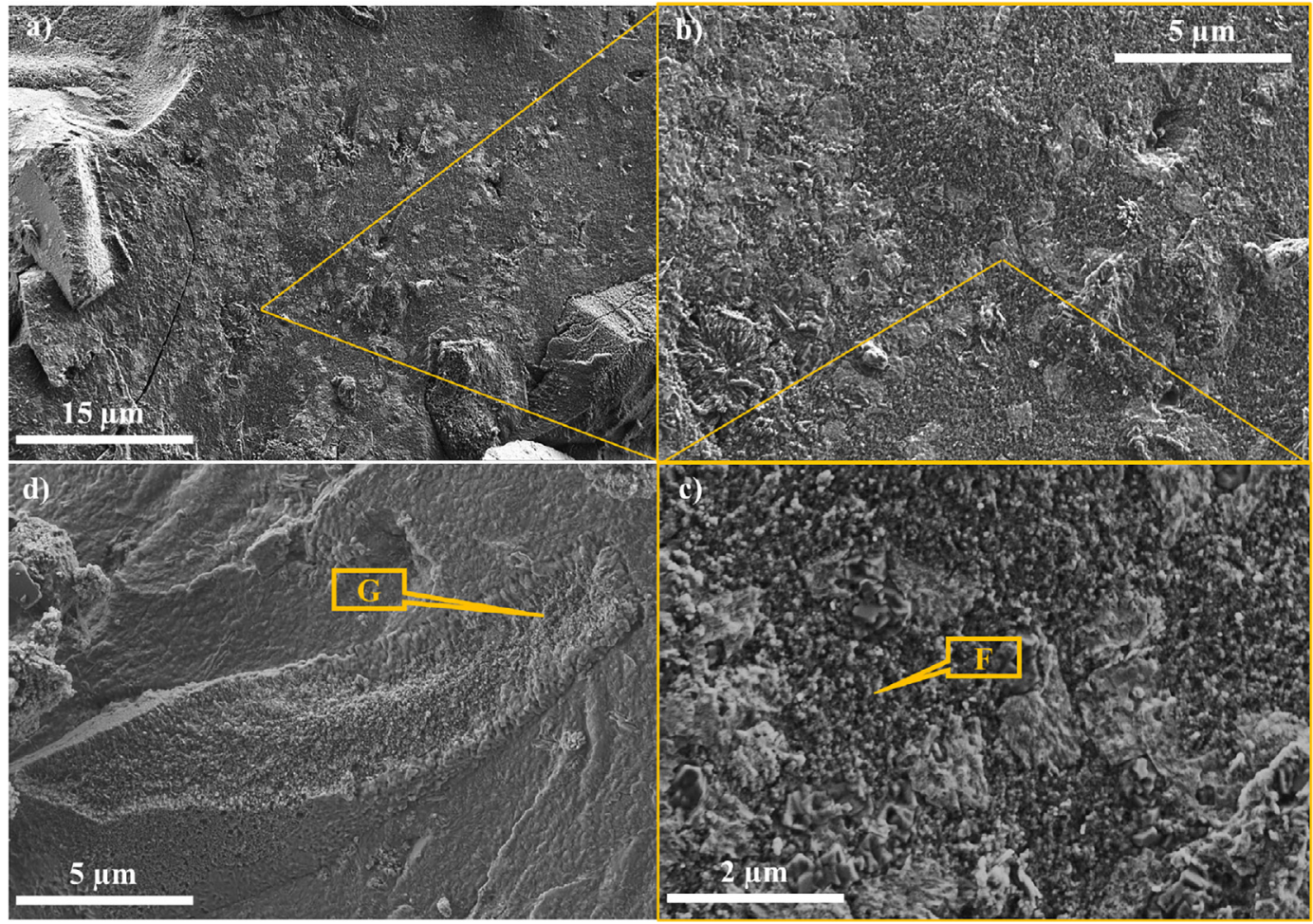

Fig. 11. FESEM micrographs of the SS-1.46 paste.

Table 7

Molar content (in \%) of the elements at points related to spots F from SS-1.46 paste.

\begin{tabular}{|c|c|c|c|c|c|c|c|}
\hline \multirow[t]{2}{*}{ Spot } & \multicolumn{6}{|c|}{ Element (molar, \%) } & \multirow[t]{2}{*}{ TOTAL (\%) } \\
\hline & $\mathrm{Si}$ & $\mathrm{Al}$ & $\mathrm{Na}$ & $\mathrm{Ca}$ & K & $\mathrm{Mg}$ & \\
\hline Spot F - 1 & 35.14 & 8.12 & 18.93 & 33.03 & 0.85 & 3.93 & 100 \\
\hline Spot F - 2 & 34.92 & 8.72 & 19.37 & 32.82 & 0.00 & 4.17 & 100 \\
\hline Spot F - 3 & 35.84 & 8.26 & 20.38 & 31.27 & 0.73 & 3.51 & 100 \\
\hline Spot F - 4 & 36.48 & 8.49 & 18.93 & 32.01 & 0.64 & 3.45 & 100 \\
\hline Spot F - 5 & 36.85 & 7.69 & 19.75 & 32.82 & 1.01 & 1.88 & 100 \\
\hline Spot F - 6 & 37.48 & 7.72 & 19.89 & 32.16 & 0.84 & 1.91 & 100 \\
\hline
\end{tabular}

Table 8

Molar content (in \%) of the elements at points related to spots G from SS-1.46 paste.

\begin{tabular}{|c|c|c|c|c|c|c|c|}
\hline \multirow[t]{2}{*}{ Spot } & \multicolumn{6}{|c|}{ Element (molar, \%) } & \multirow[t]{2}{*}{ TOTAL (\%) } \\
\hline & $\mathrm{Si}$ & $\mathrm{Al}$ & $\mathrm{Na}$ & $\mathrm{Ca}$ & $\mathrm{K}$ & $\mathrm{Mg}$ & \\
\hline Spot G - 1 & 32.95 & 13.64 & 2.87 & 37.20 & 0.50 & 12.84 & 100 \\
\hline Spot G - 2 & 30.04 & 14.04 & 5.75 & 34.81 & 0.00 & 15.37 & 100 \\
\hline Spot G - 3 & 23.97 & 11.61 & 13.97 & 30.93 & 0.00 & 19.52 & 100 \\
\hline Spot G - 4 & 26.48 & 14.76 & 10.77 & 25.84 & 0.00 & 22.15 & 100 \\
\hline Spot G - 5 & 33.96 & 9.06 & 17.92 & 31.67 & 0.72 & 6.67 & 100 \\
\hline Spot G - 6 & 29.87 & 14.47 & 6.05 & 31.41 & 0.57 & 17.63 & 100 \\
\hline Spot G - 7 & 26.84 & 14.98 & 9.59 & 26.38 & 0.00 & 22.22 & 100 \\
\hline Spot G - 8 & 23.43 & 13.85 & 10.57 & 29.61 & 0.00 & 22.55 & 100 \\
\hline Spot G - 9 & 26.81 & 11.97 & 12.34 & 30.84 & 0.00 & 18.04 & 100 \\
\hline Spot $G-10$ & 32.16 & 9.88 & 17.57 & 30.62 & 0.66 & 9.11 & 100 \\
\hline
\end{tabular}

amorphous and dense structure, highlighted in the magnification at Spot F (Fig. 11c). A comparison of Fig. 11c to Fig. 6c (SCSA1.46-24) reveals that the compactness of the former was slightly lower than that found for the SCSA paste. The formed gel in the SS paste was also similar to the ones observed in the SCSA pastes. The molar ratios of the gel on SS-1.46 were: $\mathrm{Ca} / \mathrm{Si}=0.90 \pm 0.04, \mathrm{Al} /$ $\mathrm{Si}=0.23 \pm 0.02, \mathrm{Na} / \mathrm{Al}=2.40 \pm 0.16$ and $\mathrm{Mg} / \mathrm{Si}=0.09 \pm 0.03$. Table 7 brings the elements molar content to calculate these ratios from
Spot F. The Ca/Si ratio was slightly lower than those for the SCSA pastes, probably due to the chemical combination of more silica from the SS solution. A BFS particle covered with reaction products was observed at Spot G on Fig. 11d. The chemical composition for this spot was: $\mathrm{Ca} / \mathrm{Si}=1.09 \pm 0.13, \mathrm{Al} / \mathrm{Si}=0.45 \pm 0.11, \mathrm{Na} / \mathrm{Al}=1.19 \pm$ 0.26 and $\mathrm{Mg} / \mathrm{Si}=0.64 \pm 0.26$. Table 8 shows the molar content of elements from EDS results for Spot G. A comparison of Spot G to Spot $\mathrm{F}$ showed that the former presented higher ratios of $\mathrm{Ca} / \mathrm{Si}$, 
$\mathrm{Al} / \mathrm{Si}$ and $\mathrm{Mg} / \mathrm{Si}$ than the latter. The more relative presence of $\mathrm{Ca}, \mathrm{Al}$ and $\mathrm{Mg}$ with respect to Si suggests that the BFS particle was partially reacted.

\section{Conclusions}

SCSA was successfully utilised as a silica source to produce the alkaline activating reagent for manufacturing BFS-based AAM materials by means of partial dissolution in a thermal bottle. The release of heat due to the dissolution of $\mathrm{NaOH}$ in water facilitates the dissolution of silica from SCSA. Furthermore, the obtained suspensions yielded good behaviour as an activating reagent with no filtering required, thus facilitating their implementation in AAMs. Compressive strength tests of the mortars showed that the optimum time for dissolving the $\mathrm{NaOH} / \mathrm{SCSA}$ suspension in the thermal bottle $(\tau)$ was $24 \mathrm{~h}$. The optimum amount of SCSA $(\varepsilon)$ was 1.46 . Although the SCSA samples possessed lower mechanical properties compared to the specimens produced with the commonly used $\mathrm{NH} / \mathrm{SS}$ solution, the ash-based systems showed significantly better results than the samples prepared with only $\mathrm{NaOH}$. Furthermore, the alkaline treatment of SCSA in the thermal bottle with $\mathrm{NaOH}$ produced a very reactive alkaline activator for BFS-based AAMs. It can be concluded from the microstructural studies that the SCSA pastes presented characteristics that were similar to the matrices obtained with an SS-based reagent. Dense and amorphous gels with comparable $\mathrm{Ca} / \mathrm{Si}, \mathrm{Al} / \mathrm{Si}$ and $\mathrm{Na} / \mathrm{Al}$ molar ratios were also identified.

\section{Conflict of interest}

None.

\section{Acknowledgments}

The authors would like to thank CNPq processo $\mathrm{n}^{\circ}$ 401724/2013-1 and CNPq processo $\mathrm{n}^{\circ} 140779 / 2015-0$. The authors would also like to thank the Electron Microscopy Service of the Universitat Politècnica de València.

\section{References}

[1] F. Pacheco-Torgal, J.A. Labrincha, C. Leonelli, A. Palomo, P. Chindaprasirt Handbook of Alkali-activated Cements, Mortars and Concretes, first ed, Woodhead Publishing, Cambridge, 2015.

[2] J.L. Provis, J.S.J. van Deventer, Alkali Activated Materials: State-of-the-Art Report, RILEM TC 224-AAM, Springer, Dordrecht, 2014.

[3] I. Kourti, D.A. Rani, D. Deegan, A.R. Boccaccini, C.R. Cheeseman, Production of geopolymers using glass produced from DC plasma treatment of air pollution control (APC) residues, J. Hazard. Mater. 176 (2010) 704-709.

[4] S.A. Bernal, E.D. Rodríguez, A.P. Kirchheim, J.L. Provis, Management and valorisation of wastes through use in producing alkali-activated cement materials, J. Chem. Technol. Biotechnol. 91 (2016) 2635-12388.

[5] N. Toniolo, A.R. Boccaccini, Fly ash-based geopolymers containing added silicate waste. a review, Ceram. Int. 43 (2017) 14545-14551.

[6] Food and Agriculture Organization of the United Nations (FAOSTAT), <http:// www.fao.org/faostat/en/\#home>, (accessed 21.09.17).

[7] M. Frías, E. Villar-Cociña, E. Valencia-Morales, Characterisation of sugar cane straw waste as pozzolanic material for construction: calcining temperature and kinetic parameters, Waste Manage. 27 (2007) 533-538.

[8] F. Martirena, J. Monzó, Vegetable ashes as Supplementary Cementitious Materials, Cem. Concr. Res., (2017), In Press.

[9] J.C.B. Moraes, J.L.P. Melges, J.L. Akasaki, M.M. Tashima, L. Soriano, J. Monzó, M. V. Borrachero, J. Payá, Pozzolanic reactivity studies on a biomass-derived waste from sugar cane production: sugar cane straw ash (SCSA), ACS Sustainable Chem. Eng. 4 (2016) 4273-4279.

[10] J.C.B. Moraes, J.L. Akasaki, J.L.P. Melges, J. Monzó, M.V. Borrachero, L. Soriano, J. Payá, M.M. Tashima, Assessment of sugar cane straw ash (SCSA) as pozzolanic material in blended Portland cement: microstructural characterization of pastes and mechanical strength of mortars, Constr. Build. Mater. 94 (2015) 670-677.

[11] G.A. Calligaris, M.K.K.D. Franco, L.P. Aldrige, M.S. Rodrigues, A.L. Beraldo, F, Yokaichiya, X. Turrillas, L.P. Cardoso, Assessing the pozzolanic activity of cements with added sugar cane straw ash by synchrotron X-ray diffraction and Rietveld analysis, Constr. Build. Mater. 98 (2015) 44-50.

[12] A. Guzmán, C. Gutiérrez, V. Amigó, R.M. Gutiérrez, S. Delvasto, Valoración puzolánica de la hoja de la caña de azúcar, Mater. Constr. 61 (2011) 213-225.

[13] J.C.B. Moraes, M.M. Tashima, J.L. Akasaki, J.L.P. Melges, J. Monzó, M.V. Borrachero, L. Soriano, J. Payá, Increasing the sustainability of alkaliactivated binders: The use of sugar cane straw ash (SCSA), Constr. Build. Mater. 124 (2016) 148-154.

[14] A. Nazari, J. Sanjayan, Handbook of Low Carbon Concrete, ButterworthHeinemann, Woburn, 2016.

[15] B.C. McLellan, R.P. Williams, J. Lay, A. van Riessen, G.D. Corder, Costs and carbon emissions for Geopolymer pastes in comparison to ordinary Portland cement, J. Clean. Prod. 19 (2011) 1080-1090.

[16] G. Habert, J.B. d'Espinose de Lacaillerie, N. Roussel, An environmental evaluation of geopolymer based concrete production: reviewing current research trends, J. Cleaner Prod. 19 (2011) 1229-1238.

[17] L.K. Turner, F.G. Collins, Carbon dioxide equivalent (CO2-e) emissions: a comparison between geopolymer and OPC cement concrete, Constr. Build. Mater. 43 (2013) 125-130.

[18] J.L. Provis, A. Palomo, C. Shi, Advances in understanding alkali-activated materials, Cem. Concr. Res. 78 (2015) 110-115.

[19] J.L. Provis, Alkali-activated materials, Cem. Concr. Res., (2017), In press.

[20] N. Bouzón, J. Paya, M.V. Borrachero, L. Soriano, M.M. Tashima, J. Monzó, Refluxed rice husk ash/NaOH suspension for preparing alkali activated binders, Mater. Lett. 115 (2014) 72-74.

[21] J.M. Mejía, R.M. Gutiérrez, F. Puertas, Rice husk ash as a source of silica in alkali-activated fly ash and granulated blast furnace slag systems, Mater. Constr. 63 (2013) 361-375.

[22] J.M. Mejía, R.M. Gutiérrez, C. Montes, Rice husk ash and spent diatomaceous earth as a source of silica to fabricate a geopolymeric binary binder, J. Cleaner Prod. 118 (2016) 133-139.

[23] F. Puertas, M. Torres-Carrasco, Use of glass waste as an activator in the preparation of alkali-activated slag. Mechanical strength and paste characterisation, Cem. Concr. Res. 57 (2014) 95-104.

[24] M. Torres-Carrasco, F. Puertas, Waste glass in the geopolymer preparation. mechanical and microstructural characterisation, J. Clean. Prod. 90 (2015) 397-408.

[25] H.K. Tchakouté, C.H. Rüscher, M. Hinsch, J.N.Y. Djobo, E. Kamseu, C. Leonelli, Utilization of sodium waterglass from sugar cane bagasse ash as a new alternative hardener for producing metakaolin-based geopolymer cement, Chem. Erde 77 (2017) 257-266.

[26] UNE-EN 196-1 2005, Methods of Testing Cement - Part 1, Determination of Strength, 2005.

[27] C. Shi, P.V. Krivenko, D. Roy, Alkali-Activated Cements and Concretes, Taylor \& Francis, Abingdon, 2006.

[28] I. Ismail, S.A. Bernal, J.L. Provis, R.S. Nicolas, S. Hamdan, J.S.J. van Deventer, Modification of phase evolution in alkali-activated blast furnace slag by the incorporation of fly ash, Cem. Concr. Compos. 45 (2014) 125-135.

[29] A. Fernández-Jiménez, F. Puertas, Structure of calcium silicate hydrates formed in alkaline-activated slag: influence of the type of alkaline activator, J. Am. Ceram. Soc. 86 (2003) 1389-1394.

[30] S.A. Bernal, R.M. Gutierrez, J.L. Provis, V. Rose, Effect of silicate modulus and metakaolin incorporation on the carbonation of alkali silicate-activated slags, Cem. Concr. Res. 40 (2010) 898-907.

[31] A.F. Abdalqader, F. Jin, A. Al-Tabbaa, Development of greener alkali-activated cement: utilisation of sodium carbonate for activating slag and fly ash mixtures, J. Cleaner Prod. 113 (2016) 66-75.

[32] X. Gao, Q.L. Yu, H.J.H. Brouwers, Reaction kinetics, gel character and strength of ambient temperature cured alkali activated slag-fly ash blends, Constr. Build. Mater. 80 (2015) 105-115.

[33] J.I. Escalante-García, A.F. Fuentes, A. Gorokhovsky, P.E. Fraire-Luna, G. Mendonza-Suarez, Hydration products and reactivity of blast-furnace slag activated by various alkalis, J. Am. Ceram. Soc. 86 (2003) 2148-2153.

[34] A. Buchwald, H. Hilbig, C. Kaps, Alkali-activated metakaolin-slag blendsperformance and structure in dependence of their composition, J. Mater. Sci. 42 (2007) 3024-3032. 